\title{
The CNGCb and CNGCd genes from Physcomitrella patens moss encode for thermosensory calcium channels responding to fluidity changes in the plasma membrane
}

\author{
Andrija Finka $\cdot$ Pierre Goloubinoff
}

Received: 8 April 2013 /Revised: 29 April 2013 / Accepted: 30 April 2013 /Published online: 12 May 2013

(C) The Author(s) 2013. This article is published with open access at Springerlink.com

\begin{abstract}
Land plants need precise thermosensors to timely establish molecular defenses in anticipation of upcoming noxious heat waves. The plasma membrane-embedded cyclic nucleotide-gated $\mathrm{Ca}^{2+}$ channels (CNGCs) can translate mild variations of membrane fluidity into an effective heat shock response, leading to the accumulation of heat shock proteins (HSP) that prevent heat damages in labile proteins and membranes. Here, we deleted by targeted mutagenesis the $C N G C d$ gene in two Physcomitrella patens transgenic moss lines containing either the heat-inducible HSP-GUS reporter cassette or the constitutive UBI-Aequorin cassette. The stable CNGCd knockout mutation caused a hyperthermosensitive moss phenotype, in which the heatinduced entry of apoplastic $\mathrm{Ca}^{2+}$ and the cytosolic accumulation of GUS were triggered at lower temperatures than in wild type. The combined effects of an artificial membrane fluidizer and elevated temperatures suggested that the gene products of $C N G C d$ and $C N G C b$ are paralogous subunits of $\mathrm{Ca}^{2+}$ channels acting as a sensitive proteolipid thermocouple. Depending on the rate of temperature increase, the duration and intensity of the heat priming preconditions, terrestrial plants may thus acquire an array of HSP-based thermotolerance mechanisms against upcoming, otherwise lethal, extreme heat waves.
\end{abstract}

Keywords Plant heat shock response $\cdot$ Acquired thermotolerance $\cdot \mathrm{Ca}^{2+}$ channels $\cdot$ Physcomitrella patens . Heat shock proteins

Electronic supplementary material The online version of this article (doi:10.1007/s12192-013-0436-9) contains supplementary material, which is available to authorized users.

A. Finka $\cdot$ P. Goloubinoff $(\bowtie)$

Department of Plant Molecular Biology, University of Lausanne, CH-1015 Lausanne, Switzerland

e-mail: Pierre.Goloubinoff@unil.ch

\begin{abstract}
Abbreviations
CNGC Cyclic nucleotide-gated channel

HSR Heat shock response

HSPs Heat shock proteins

BA Benzyl alcohol

$E_{50} \quad$ Physiological temperature at which half of the maximal activatory effect is observed

$\mathrm{IT}_{50}$ Excessive temperature at which half of the maximal inhibitory effect is observed
\end{abstract}

\section{Introduction}

On the break of a hot summer day, land plants in dry midlatitude climates (Peel et al. 2007) need sensitive thermosensors to detect mild increments in the ambient temperature and trigger an appropriate heat shock response (HSR) in anticipation of upcoming extreme midday temperatures (Mittler et al. 2012). At the cellular level, the HSR is an appropriate accumulation of a complex network of protective heat shock proteins (HSPs), the most abundant of which are molecular chaperones that can prevent heatinduced misfolding and aggregation of labile proteins (Hinault et al. 2006; Sharma et al. 2010; Finka et al. 2011) and protect membranes from heat damage (Torok et al. 1997). At physiological temperatures, proteins and membranes are expected to be optimally stable and functional. At high excessive temperatures, the increased thermal movements of macromolecules may transiently dissociate protein complexes, unfold polypeptides, and decrease lipid order in membranes thus leading to the formation of inactive, potentially toxic, protein aggregates and hyperfluid membranes prone to disruption (Mittler and Blumwald 2010). Hence, it is of primary importance that plant cells can anticipate an upcoming noxious heat shock by detecting mild increments in the ambient temperature before labile macromolecular 
complexes are damaged and timely establish effective molecular defenses in the form of detoxifying enzymes, such as ascorbate peroxidase and of unfolding chaperones, such as Hsp101, Hsp90, Hsp70, and Hsp60, which can avert heatinduced protein aggregations (Finka et al. 2011; Mittler et al. 2012; Sharma et al. 2011), as well as small HSPs that can prevent protein aggregation (Veinger et al. 1998) and protect membranes against hyperfluidity (Torok et al. 1997; Horvath et al. 1998, 2012).

Because the massive accumulation of HSPs has a very high cellular cost, both in terms of energy and resources, the HSR needs to be finely tuned. Therefore, plant cells need precise thermosensors that can react to mild temperature increments, for examples when the sun rises, and send an appropriate timely signal to synthesize within $2-8 \mathrm{~h}$ protective HSPs to withstand the noxious heat at noon. During an abrupt continuous heat shock, as in the laboratory, the levels of HSP mRNAs in the plant cells strongly increase during the first $30 \mathrm{~min}$ and then rapidly decrease to reach ground levels within 1-2 $\mathrm{h}$, despite the ongoing heat-inducing conditions (Saidi et al. 2005, 2009; Finka et al. 2011). Yet, when plants are treated as in nature with a gradual increase of temperatures during several consecutive hours, to slowly reach the noxious temperatures within $6 \mathrm{~h}$ (Larkindale and Vierling 2008), this produces more HSP mRNAs and better plant survival than a shorter and milder stepwise heat priming treatment (Larkindale and Vierling 2008). This suggests that during the gradual increments of the heat, plants may use a series of distinct heat sensors that become successively activated at different temperature thresholds and thus generate successive waves of HSP synthesis. Such a scenario might result in the observed effective continuous accumulation of protective HSPs, despite the transient nature of the heat activation process (Larkindale and Vierling 2008; Saidi et al. 2009). It is thus central to understand the molecular nature of the primary heat sensors and resolve how, despite the transient entry of $\mathrm{Ca}^{2+}$ and mRNA accumulation within minutes, plant cells may increase their HSP load during hours and develop acquired thermotolerance lasting days (Cohen-Peer et al. 2010).

At physiological temperatures, the plant heat shock transcription factors (HSFs) are inactive. Like in animals and fungi, they are hypo-phosphorylated monomers, which may be found in association with cytosolic Hsp90s and Hsp70s (Hahn et al. 2011; Scharf et al. 2012). Under heat shock conditions, the higher plant non-heat-inducible HSFA1a and the heat-inducible HSFA2 become hyper-phosphorylated and may form heterocomplexes that rapidly enter the nucleus, where they may specifically activate the transcription of about a thousand HSP genes ( $\mathrm{Li}$ et al. 2010; Busch et al. 2005). In Arabidopsis, the overexpression of SUMO1, which binds to the heat-inducible HSFA2, represses the transcription of reporters transgenes from Hsp17.4 and
Hsp17.6 and Hsp101 promoters and decreases plant acquired thermotolerance (Cohen-Peer et al. 2010).

To specifically transcribe the thousand or so of heat-induced genes in plants (Finka et al. 2011; Mittler et al. 2012), the heatactivated plant HSFs must specifically bind to particular DNA motives, also called heat shock elements (HSEs), upstream to each of the 1,780 HSP genes in Arabidopsis (following $90 \mathrm{~min}$ at $38^{\circ} \mathrm{C}$ ) or 1,509 in wheat (following $60 \mathrm{~min}$ at $40^{\circ} \mathrm{C}$ ) (Finka et al. 2011; Qin et al. 2008).

Under conditions that are unchallenging for the HSP genes, histones forming nucleosomes are often considered as a transcriptional roadblock (Kumar and Wigge 2010). The binding of active HSFs to HSE, which needs to occur at nucleosome-free stretches of DNA (Petesch and Lis 2008; Petesch and Lis 2012) can activate chromatin remodeling complexes to modify nearby bound histones (Clapier and Cairns 2009), thereby unleashing the bound RNA polymerase to massively transcribe the HSP genes (Mittler et al. 2012; Petesch and Lis 2012).

In contrast to histones, which are likely to be the most downstream components of the heat shock signaling pathway to dissociate from the transcription start sites of HSR genes upon command form DNA-bound activated HSFs, there is strong evidence that the most upstream components are heatsensitive membrane receptors consisting of the cyclic nucleotide-gated calcium channels (CNGCs) (Gao et al. 2012; Finka et al. 2012; Tunc-Ozdemir et al. 2012). A growing body of evidence has accumulated, pointing at a fluiditybased thermosensory mechanism in the plasma membrane of land plant cells (Saidi et al. 2011; Mittler et al. 2012), which can act as an effective early warning system during physiological warming, to trigger a timely buildup of HSP-based protections, in anticipation of upcoming damaging conditions. The plant plasma membrane apparently contains distinct populations of embedded thermosensors. Thus, a mild temperature increase can activate and depolarize one type of $\mathrm{Ca}^{2+}$ channels, while the others still remain fully potent until exposed to higher temperatures (Saidi et al. 2005; Finka and Goloubinoff 2013). In confirmation, electrophysiology shows the presence of three distinct thermoresponsive $\mathrm{Ca}^{2+}$ channels in the plasma membrane of moss protoplasts, with the distinct conductances of 75pS, 33pS, and 15pS (Finka et al. 2012).

A knockout of CNGC6 in Arabidopsis thaliana resulted in plants with vegetative tissues showing a decreased tolerance to heat stress (Gao et al. 2012). This appears analogous to the increased heat stress sensitivity that has been observed in the pollen of CNGC16 mutants (Tunc-Ozdemir et al. 2012). Among the land plants, the $A$. thaliana genome encodes for 20 closely related CNGC genes that clearly cluster with eight homologous CNGC genes in the genome of Physcomitrella patens and five in the genome of Selaginella moellendorffii. All have six conserved transmembrane helices, a putative cyclic nucleotide-binding 
domain, a putative $\mathrm{Ca}^{+2}$-calmolulin-binding domain, and a characteristic "phosphate-binding cassette" (Zelman et al. 2012; Wheeler and Brownlee 2008). Remarkably, no protein with similar enough sequences and reuniting similar putative domains can be found in the genome of liverwort Marchantia polymorpha and in algae (Zelman et al. 2012; Wheeler and Brownlee 2008; Finka et al. 2012), suggesting that the evolution of this class of cyclic nucleotide-gated $\mathrm{Ca}^{2+}$ channels in the plant kingdom is related to the adaptation of photosynthetic organisms to the harsh atmospheric conditions of the terrestrial environment.

Confirming the link between CNGCs and land plant heat sensing, a site-directed CNGCb knockout mutant in P. patens moss and the homozygote interruption mutants in the orthologous Arabidopsis genes AtCNGC2 and AtCNGC4 (see Supplementary Fig. S1) display dysregulated hyperthermosensitive responses and hyper-thermosensitive profile of acquired thermotolerance (Finka et al. 2012). Noticeably, electrophysiology shows that the $C N G C b$ knockout mutant is devoid of the $75 \mathrm{pS}$ channel, whereas the remaining $33 \mathrm{pS}$ and $15 \mathrm{pS} \mathrm{Ca}^{2+}$ channels have increased open probabilities, compared to the wild type (WT) moss membranes. Thus, while $\mathrm{CNGCb}$ is likely a major subunit component of the $75 \mathrm{pS}$ channel, it may be a minor component of other two channels and may be replaced by the other orthologous CNGCs, leading to the dysregulated thermoresponsive phenotypes of the $33 \mathrm{pS}$ and $15 \mathrm{pS}$ channels in the $\mathrm{CNGCb}$ mutant.

Here, we show that the $P$. patens $\mathrm{CNGCd}$ gene, which is a close ortholog of $\mathrm{CNGCb}$, carries a similar thermosensory function. Whereas either the CNGCd or the CNGCb deletion caused a hyper-thermosensitive response at mild nondamaging temperatures, they did not affect the plant cell sensitivity to excessive damaging temperatures. In contrast, application of an artificial membrane fluidizer caused a hyperthermosensitive response, both at mild and at excessively high temperatures, while it further exacerbated hyperthermosensitive response in mutants implying a cumulative effect between increased membrane hyperfluidity and $\mathrm{Ca}^{2+}$ leakiness. Thus, the plant heat sensor acts as a proteolipid thermocouple (Horvath et al. 2012), responding to mild temperature-induced changes in the fluidity of the surrounding plasma membrane by sending a specific HSR to transcribe the HSP genes and thus establish acquired thermotolerance.

\section{Results}

The PpCNGCd loss-of-function moss mutant yields mildly chlorotic, but fertile gametophores

We used the reporter moss line Hsp-GUS (Saidi et al. 2005), referred here as the "wild type" strain (WT) and deleted most of the PpCNGCd gene by targeted gene replacement
(Schaefer and Zryd 1997). Following antibiotic selection, ten stable transformants were identified and the genomic DNA was isolated. Southern blot analysis of one mutant, $\triangle C N G C d$, confirmed that the CNGCd gene was disrupted by the stable integration of multiple copies of the selective marker (Fig. 1, lower left). In contrast to the growthimpaired $\triangle \mathrm{CNGCb}$ mutant (Finka et al. 2012), the $\triangle \mathrm{CNGCd}$ protonema grew at similar rates as the WT moss. Although the $\triangle \mathrm{CNGCd}$ gametophores were slightly more chlorotic (Fig. 1, lower right), the transition to gametophores took place at about the same time as the $\triangle \mathrm{CNGCb}$ and WT strains and $\triangle \mathrm{CNGCd}$ apparently generated a similar number of capsules (Fig. 1, arrow heads) with viable spores.

CNGCd controls heat-induced $\mathrm{Ca}^{2+}$ entry and the expression of HSPs

Electrophysiology of WT and $\triangle \mathrm{CNGCb}$ moss protoplasts has shown that mild temperature upshifts from 25 up to $32{ }^{\circ} \mathrm{C}$

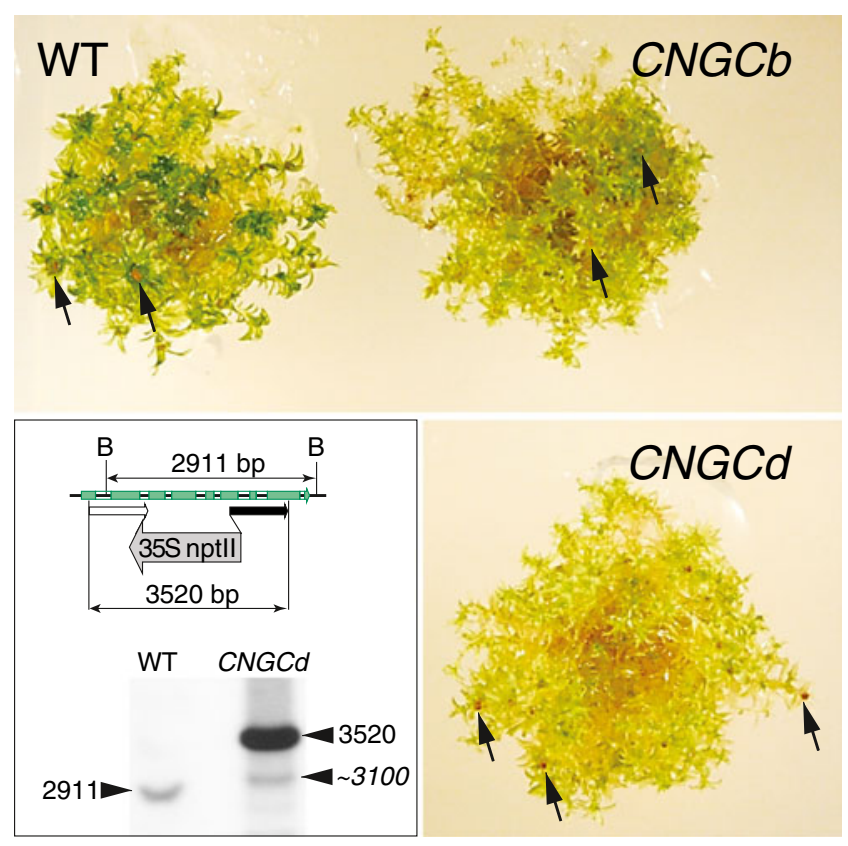

Fig. 1 The $C N G C d$ loss-of-function moss mutant is mildly chlorotic but with fertile gametophores. Morphological appearance of 3-monthold moss gametophores of WT (upper left), $\triangle C N G C b$ (upper right), and $\triangle C N G C d$ (lower right) strains bearing spore capsules (arrows). Inset: schematic representation of the targeted genomic moss $C N G C d$ locus in the WT strain and the $C N G C d$ mutant (upper). The BglII restriction sites $(B)$, which are in the $5^{\prime}$ (white box) and the $3^{\prime}$ (black box) fragments of the $C N G C d$ gene, are indicated. The southern blot from BglII-digested genomic DNA from the WT $C N G C d$ mutant strain probed with PCR-amplified segment corresponding to the $3^{\prime}$ (black arrow). The BglII pattern shows that a 2,911-bp genomic fragment in the WT CNGCd gene has been mutated into a 3,520-bp-long 5'35 SnptII- 3 ' fragment of the core region of the $C N G C d$ locus, which became interrupted by a multiple copy insertion, creating also a single flanking region of about 3,100 bp (arrowheads) 
caused the transient entry of apoplastic $\mathrm{Ca}^{2+}$ through three distinct temperature-sensitive $\mathrm{Ca}^{2+}$ channels in the moss cell plasma membrane (Saidi et al. 2009; Finka et al. 2012). Here, we used a less sensitive, but a noninvasive, whole tissue assay to measure temperature-dependent fluctuations of cytoplasmic $\mathrm{Ca}^{2+}$ in intact plant tissues. To this aim, we first introduced into the $\triangle \mathrm{CNGCd}$ strain a stable UBI-AEQ cassette expressing an aequorin reporter from the strong constitutive ubiquitin promoter, which, in the presence of coelenterazine and $\mathrm{Ca}^{2+}$ ions, emits light thereby reporting fluctuations of cytoplasmic $\mathrm{Ca}^{2+}$ concentration (Plieth 2006; Saidi et al. 2009). Whereas a mild temperature upshift from 25 to $34{ }^{\circ} \mathrm{C}$ did not cause the entry of measurable amounts of apoplastic $\mathrm{Ca}^{2+}$ into the cytoplasm of the WT strain (Saidi et al. 2009; Finka et al. 2012), a significant $\mathrm{Ca}^{2+}$ signal was observed in the cytosol of both $\triangle C N G C b$ and $\triangle C N G C d$ strains (Fig. 2a). Confirming the hyper-thermoresponsive nature of both mutant strains, a stronger temperature upshift, from 25 to $36{ }^{\circ} \mathrm{C}$, caused a massive $\mathrm{Ca}^{2+}$ entry in the cytoplasm of both $\triangle C N G C b$ and $\triangle C N G C d$ strains, and in contrast, a significant, yet much milder entry of apoplastic $\mathrm{Ca}^{2+}$ into the cytoplasm of the WT strain was observed.

These data confirm that both $\mathrm{CNGCb}$ and $\mathrm{CNGCd}$ are primary components of specific $\mathrm{Ca}^{2+}$ channels in the plasma membrane acting in plant cells as thermosensors. They apparently react to temperature-induced fluidity changes in the surrounding membranes, by allowing the transient entry of apoplastic $\mathrm{Ca}^{2+}$, to trigger a specific HSR in the form of accumulating HSPs. Whereas the time range for thermally induced $\mathrm{Ca}^{2+}$ fluctuations is in the order of several minutes (Saidi et al. 2009; Finka et al. 2012), the time range for thermally induced HSP accumulation, leading to acquired thermotolerance is in the order of several hours. We therefore next addressed the effect of the gene deletions in the $\mathrm{CNGCb}$ and CNGCd thermosensors, on the heat induction profile of the moss HSPs, using the heat-inducible HSP-GUS expression cassette, as a general reporter for the conditional HSP expression in moss (Saidi et al. 2005, 2007, 2009; Finka et al. 2012).

Whereas in the HSP-GUS (WT) control strain, a 60-min abrupt temperature upshift from 25 to $32{ }^{\circ} \mathrm{C}$ did not induce any GUS, and half optimal GUS accumulation was observed at $34.8^{\circ} \mathrm{C}$, in the HSP-GUS $C N G C d$ strain, the same two thresholds were reached at 30 and $34{ }^{\circ} \mathrm{C}$, respectively, and in the HSP-GUS $C N G C b$ strain, at less than 28 and $31.5^{\circ} \mathrm{C}$, respectively (Fig. 2c). Thus, both CNGC mutants were hyper-thermoresponsive to a mild temperature rise, both in terms of $\mathrm{Ca}^{2+}$ entry within minutes and of HSP accumulation within hours. This indicates that heatinduced HSP expression at $36{ }^{\circ} \mathrm{C}$ is a direct consequence of a prior heat-induced entry of apoplastic $\mathrm{Ca}^{2+}$ through the heat-responsive CNGC channels in the plasma membrane.

The genome of $P$. patens encodes for six other putative CNGC genes, which are related to $\mathrm{CNGCb}$ and $\mathrm{CNGCd}$
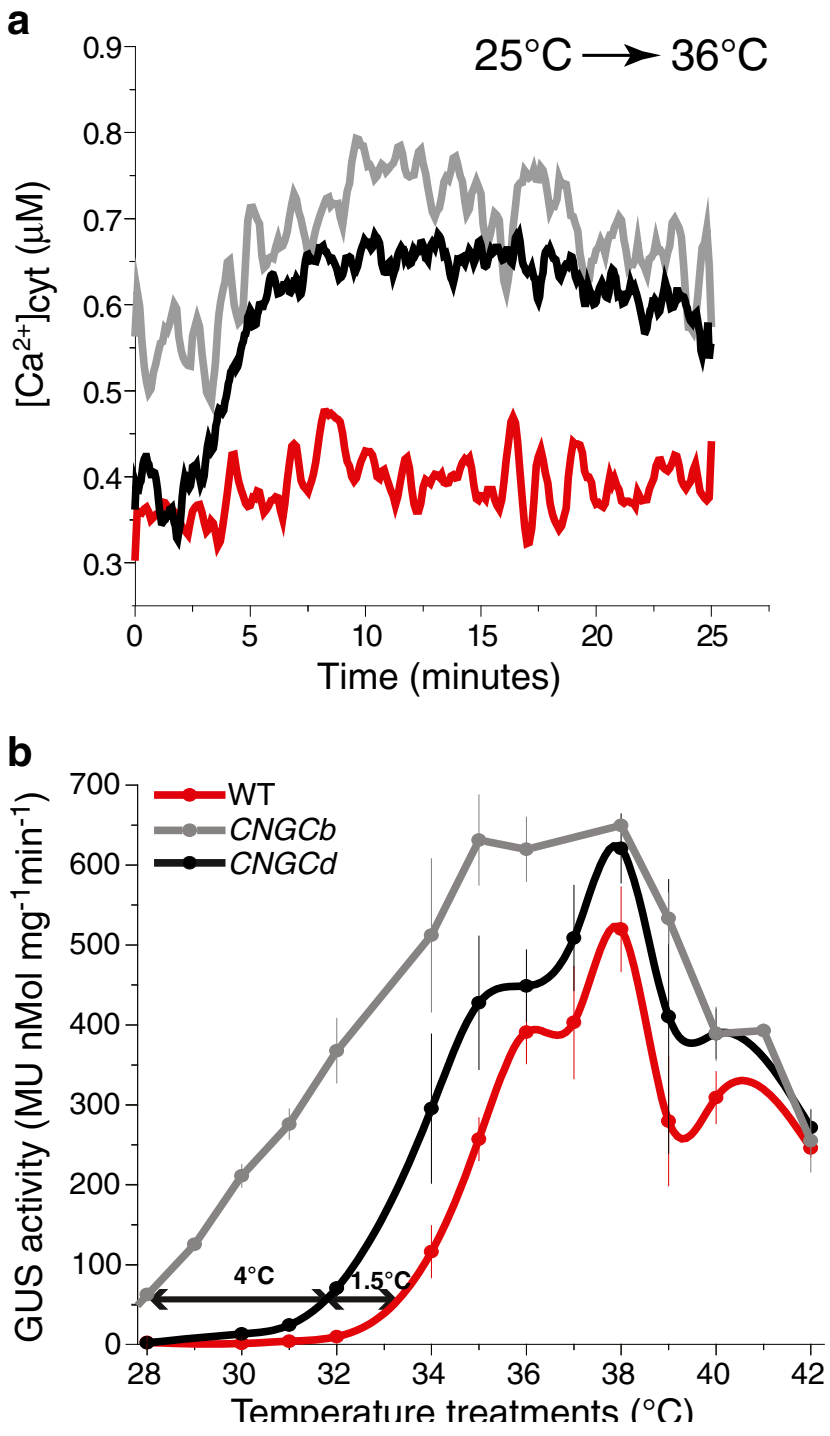

Fig. 2 Deletion of $C N G C d$ causes hyper-thermoresponsive $\mathrm{Ca}^{2+}$ influx and hyper-thermosensitive HSP expression. Recombinant aequorin-overexpressing protonemal tissues with intact CNGCs (WT), DCNGCb, and DCNGCd were grown at $25{ }^{\circ} \mathrm{C}$, preincubated with coelenterazine as in Finka et al. (2012), and then exposed continuously for the indicated time to $36{ }^{\circ} \mathrm{C}$. a Online measures of $\mathrm{Ca}^{2+}$. dependent luminescence of cytosolic aequorin recorded in WT (red line), $\triangle C N G C b$ (gray line), and $\triangle C N G C d$ (black line). b Heat-induced GUS accumulation in recombinant Hsp-GUS protonemal tissues of WT (red line), $\triangle C N G C b$ (gray line), and $\triangle C N G C d$ (black line) strains, following $1 \mathrm{~h}$ exposure at the indicated temperatures and $16 \mathrm{~h}$ at $22{ }^{\circ} \mathrm{C}$. The double arrow shows $10 \%$ of maximal GUS accumulation reached in WT at $33^{\circ} \mathrm{C}$, in $\triangle C N G C d$ at $31.5^{\circ} \mathrm{C}$, and in $\triangle C N G C b$ at $28.3{ }^{\circ} \mathrm{C}$. Means and SD are from at least three independent experiments

(Finka et al. 2012). This raises the possibility that some of functional CNGC channels are heterocomplexes composed of more than two different subunits, in different ratios, each with a different threshold of thermo-responsiveness, and that when a given CNGC subunit is missing, it might be functionally but imperfectly replaced by one of its close orthologs. 
Artificial membrane fluidization renders moss hyper-thermoresponsive

When the WT Hsp-GUS strain was incubated with the membrane fluidizer benzyl alcohol $(5 \mathrm{mM})$ and treated for $30 \mathrm{~min}$ at increasing temperatures (de Marco et al. 2005; Saidi et al. 2009; Horváth et al. 1998), this caused a general downshift of the temperature profile of Hsp-GUS accumulation, from $\mathrm{ET}_{50}=34.8{ }^{\circ} \mathrm{C}$ without BA to $32.0{ }^{\circ} \mathrm{C}$ with BA (Fig. 3). Thus, in the low range of physiological warming temperatures in WT moss, the presence of the artificial membrane fluidizer recapitulated the hyper-thermoresponsive phenotype, which was observed without $\mathrm{BA}$ in the $\mathrm{CNGCb}$ or the $\mathrm{CNGCd}$ deletion mutants. Noticeably, the $\mathrm{CNGCb} / \mathrm{d}$ deletion mutants and the WT strains showed the same degree of sensitivity to excessive temperatures, with $\mathrm{IT}_{50}$ values $42.1 \pm 0.1{ }^{\circ} \mathrm{C}$ (Fig. 3, Fig. S2). In contrast, the presence of BA downshifted the $\mathrm{IT}_{50}$ values of GUS overproduction from 42.1 to $41.3{ }^{\circ} \mathrm{C}$ in CNGCd, to $39.5{ }^{\circ} \mathrm{C}$ in $\mathrm{CNGCb}$ as compared to $39.1{ }^{\circ} \mathrm{C}$ in WT (Fig. S2B).

\section{Discussion}

As evidenced by their additive effects, the hyperthermoresponsive phenotype that was caused by the BA treatment originated from an artificial change in the membrane fluidity, as compared to the CNGC knockout mutations that did not change membrane fluidity but rather changes the quality of the CNGC protein complexes that sense the fluidity state of surrounding plasma membrane. This corroborated previous observations in fully differentiated aging moss gametophores of the HSP-GUS strain, where the heat-induced GUS expression was dramatically

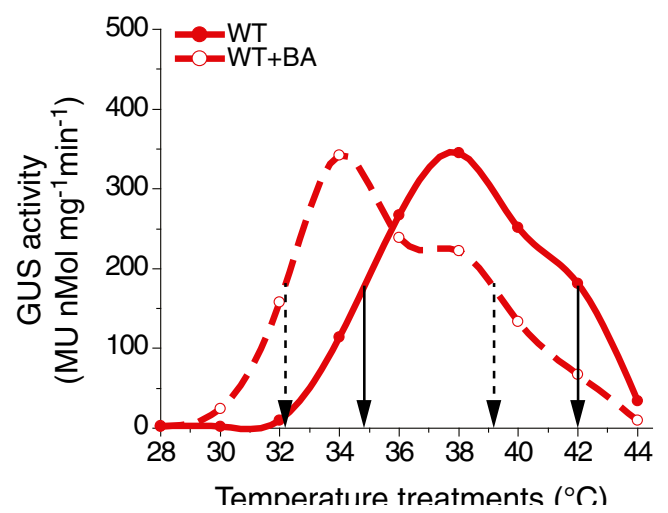

Fig. 3 The membrane fluidizer benzyl alcohol (BA) produces a hyperthermosensitive response in Hsp-GUS WT. Heat induced GUS accumulation in the Hsp-GUS WT strain following 30-min exposure at the indicated temperatures and $16 \mathrm{~h}$ at $25^{\circ} \mathrm{C}$, without (plain lines) or in the presence in the medium of $5 \mathrm{mM}$ benzyl alcohol (BA, dashed lines). Vertical dash-line and plain arrows show $\mathrm{ET}_{50}$ values and $\mathrm{IT}_{50}$ for $\mathrm{BA}$ treated and non-treated moss, respectively reduced compared to young protonema tissues, in correlation with a significantly higher content of unsaturated lipids in the young membranes (Saidi et al. 2010). Together, our data strongly suggest that both the lipid part of the plasma membrane and the embedded $\mathrm{CNGCb}$ and CNGCd proteins act as two cooperating moieties of an effective thermocouple.

Our data suggest a mechanism where mild changes in the ambient temperature cause direct fluidity changes in the plasma membrane of the plant cells, which are sensed by the embedded CNGC channels, which consequently open. This allows the transient entry of apoplastic $\mathrm{Ca}^{2+}$ ions through the channels into the cytoplasm, to interact with the cytosolic C-terminal domains of the CNGCs that contain calmodulin-binding signatures (Fischer et al. 2013; Arazi et al. 2000). Thus, the heat shock signal may propagate from the plasma membrane, likely by way of specific $\mathrm{Ca}^{2+}$-dependent calmodulins and calmodulin kinases and phospholipases (Mishkind et al. 2009; Liu et al. 2008, 2006; reviewed in Saidi et al. 2011; Mittler et al. 2012), to activate the HSFs in the cytosol and cause HSF translocation to the nucleus to specifically transcribe protective heat shock proteins, leading to acquired thermotolerance.

It has been suggested that particular histones, such as H2A.Z, which are frequently but not exclusively found associated to HSP genes, may directly sense an increase of ambient temperature (from 11 to $17{ }^{\circ} \mathrm{C}$ ), and like a molecular thermometer directly react to the temperature by dissociating from their repressory association with HSP genes, thereby allowing the active transcription of HSP genes, in particular Hsp70 (Kumar and Wigge 2010). Our finding that specific mutations in the CNGC proteins in the plasma membrane strongly affect the profile of plant cell response to temperature increments (Finka et al. 2012) and that the artificial prevention of apoplastic $\mathrm{Ca}^{2+}$ entry into the cytoplasm during the first minutes of heat shock totally prevent the HSR (Saidi et al. 2009) strongly argues against histones and histone-remodeling complexes being the primary thermosensors of the plant cells. Rather, our findings suggest that upon transiently increasing the membrane fluidity, higher temperatures trigger the transient opening of various populations of channels composed of $\mathrm{CNCGb}$ and $\mathrm{CNGCd}$ subunits, which in turn translate into a specific $\mathrm{Ca}^{2+}$ entrydependent and calmodulin-dependent heat shock signal that likely activates a calmodulin-dependent kinase (Liu et al. 2008), specifically phosphorylating and thus activating the HSFs in the cytoplasm. Once hyper-phosphorylated, the activated HSFs may enter the nucleus and bind specifically only to the HSEs.

Interestingly, mammalian cells also carry plasma membrane-embedded $\mathrm{Ca}^{2+}$ channels acting similarly as cellular thermosensors responsible to the cellular HSR. Thus, the transient receptor potential vanilloids (TRPVs) are ion channels in the plasma membrane of various neural and 
epithelial cells that are distantly related to the plant CNGCs, both types being $\mathrm{Ca}^{2+}$ channels composed of six transmembrane helices with a cytosolic calmodulin-binding domain that can apparently respond to fluidity changes, or to mild physiological warming, by sending a specific $\mathrm{Ca}^{2+}$ entrydependent signal to activate cytosolic HSF1. Upon warming, or the isothermal application of the TRPV agonist capsaicin, the TRPV-based thermosensory mechanism activates a typical HSR in the form of HSP accumulation. Moreover, the heat/fever-induced HSR is inhibited by TRPV1 siRNA, as well as by the TRPV1 antagonist capsazepine, or more generally by the external application of a $\mathrm{Ca}^{2+}$ chelator (Bromberg et al. 2013).

It is traditionally thought that the primary heat sensors in eukaryotic cells, including in plants, were some unidentified thermolabile cytosolic proteins that presumably denature under a noxious heat shock, thereby recruiting the cytosolic Hsp90 and Hsp70 and derepressing the inactive HSFs form their inhibitory association with these chaperones (Voellmy and Boellmann 2007). Yet, this mechanism is counterintuitive as it implies a dilatory induction of the cellular defenses, only once damages in proteins have occurred. In contrast, we bring here strong evidence pointing at a fluidity-based thermosensory mechanism in the plant plasma membrane of moss plant that can act as an early warning system under a physiological warming, to trigger the timely buildup of HSP-based cellular protections, in anticipation of upcoming heat damaging conditions.

\section{Material and methods}

Plasmids

\section{PpCNGCd-KO vector}

The 5' targeting fragment of PpCNGCd was amplified using ApaIF (GGGCCCTTTGCGAAAAGTATCCATCTTCTC) and XhoIR: (CTCGAGCACACAAACACAATT AGAAAATCT) and 3' targeting fragment was amplified by SpeIF (ACTAGTGTGGGCTGCTACTCGTGGG ATCGA) and SacIIR (CCGCGGAACTTGTGCTGG AAGTGTTGCGT) using Taq polymerase (Promega, Madison, WI). Resulting products were first subcloned in pGEM-T-easy vector (Promega Madison, WI) and digested with ApaI/Xho or SpeI/SacII and subcloned in two steps into corresponding sites of pBSMDII (Finka et al. 2008, 2012), to generate the PpCNGCd-KO vector. To minimize the possibility of super integration of $C N G C b$-KO cassette into HSP-GUS locus, about $10 \mu \mathrm{g}$ of $C N G C d-\mathrm{KO}$ transgene was amplified by PCR employing standard T3 and T7 primers, followed by enzymatic digestion with ApaI and SacII restriction endonucleases.
Plant material, moss transformation, chemicals, GUS, and aequorin experimentations

The moss $P$. patens transgenic lines were grown on moss solid medium and transferred when stated to liquid minimal medium as previously described (Saidi et al. 2009; Finka et al. 2012). To generate stable transgenic moss $C N G C d$ lines in the HSP-GUS background, a polyethylene glycolmediated transformation of moss protoplasts was performed using PCR-amplified $C N G C b-\mathrm{KO}$ cassette followed by G418 antibiotic selection (Schaefer and Zryd 1997). The aequorin-expressing $C N G C d$ mutant was created by introduction of pBUAzeo (Finka et al. 2012) into the previously generated $C N G C d$ mutant line by super integration of the pBUAzeo into the artificial Hsp-GUS locus.

The coelenterazine hcp, EGTA, and 4-methylumbelliferone glucoronide were purchased from Sigma (St Louis, MO, USA). GUS-specific activities, electrophysiological experimentations, and the concentration of cytosolic calcium using reconstituted aequorin system were described previously (Saidi et al. 2009; Finka et al. 2012).

Acknowledgments The University of Lausanne and the Swiss National Science Foundation grants (125502/1 and 140512/1) financed this project.

Open Access This article is distributed under the terms of the Creative Commons Attribution License which permits any use, distribution, and reproduction in any medium, provided the original author(s) and the source are credited.

\section{References}

Arazi T, Kaplan B, Fromm H (2000) A high-affinity calmodulin-binding site in a tobacco plasma-membrane channel protein coincides with a characteristic element of cyclic nucleotide-binding domains. Plant Mol Biol 42(4):591-601. doi:10.1023/a:1006345302589

Bromberg Z, Goloubinoff P, Saidi Y, Weiss YG (2013) The membraneassociated transient receptor potential vanilloid channel is the central heat shock receptor controlling the cellular heat shock response in epithelial cells. Plos One 8(2):e57149

Busch W, Wunderlich M, Schoffl F (2005) Identification of novel heat shock factor-dependent genes and biochemical pathways in Arabidopsis thaliana. Plant Journal 41(1):1-14. doi:10.1111/ j.1365-313X.2004.02272.x

Clapier CR, Cairns BR (2009) The biology of chromatin remodeling complexes. Annu Rev Biochem 78:273-304. doi:10.1146/ annurev.biochem.77.062706.153223

Cohen-Peer R, Schuster S, Meiri D, Breiman A, Avni A (2010) Sumoylation of Arabidopsis heat shock factor A2 (HsfA2) modifies its activity during acquired thermotholerance. Plant Mol Biol 74(1):33-45. doi:10.1007/s11103-010-9652-1

de Marco A, Vigh L, Diamant S, Goloubinoff P (2005) Native folding of aggregation-prone recombinant proteins in Escherichia coli by osmolytes, plasmid- or benzyl alcohol-overexpressed molecular chaperones. Cell Stress Chaperones 10(4):329-339

Finka A, Cuendet AFH, Maathuis FJM, Saidi Y, Goloubinoff P (2012) Plasma membrane cyclic nucleotide gated calcium channels 
control land plant thermal sensing and acquired thermotolerance. Plant Cell 24(8):3333-3348. doi:10.1105/tpc.112.095844

Finka A, Goloubinoff P (2013) Proteomic data from human cell cultures refine mechanisms of chaperone-mediated protein homeostasis. Cell Stress and Chaperones. doi: 10.1007/s12192-0130413-3

Finka A, Mattoo RUH, Goloubinoff P (2011) Meta-analysis of heatand chemically upregulated chaperone genes in plant and human cells. Cell Stress \& Chaperones 16(1):15-31. doi:10.1007/ s12192-010-0216-8

Finka A, Saidi Y, Goloubinoff P, Neuhaus JM, Zryd JP, Schaefer DG (2008) The knock-out of ARP3a gene affects F-actin cytoskeleton organization altering cellular tip growth, morphology and development in moss Physcomitrella patens. Cell Motility and the Cytoskeleton 65(10):769-784. doi:10.1002/Cm.20298

Fischer C, Kugler A, Hoth S, Dietrich P (2013) An IQ domain mediates the interaction with calmodulin in a plant cyclic nucleotidegated channel. Plant and Cell Physiology. doi:10.1093/pcp/pct021

Gao F, Han XW, Wu JH, Zheng SZ, Shang ZL, Sun DY, Zhou RG, Li B (2012) A heat-activated calcium-permeable channel-Arabidopsis cyclic nucleotide-gated ion channel 6-is involved in heat shock responses. Plant Journal 70(6):1056-1069. doi:10.1111/j.1365-313X.2012.04969.x

Hahn A, Bublak D, Schleiff E, Scharf KD (2011) Crosstalk between Hsp90 and Hsp70 chaperones and heat stress transcription factors in tomato. Plant Cell 23(2):741-755. doi:10.1105/tpc.110.076018

Hinault MP, Ben-Zvi A, Goloubinoff P (2006) Chaperones and proteases - cellular fold-controlling factors of proteins in neurodegenerative diseases and aging. J Mol Neurosci 30(3):249-265. doi: $10.1385 / \mathrm{Jmn} / 30: 03: 249$

Horvath I, Glatz A, Nakamoto H, Mishkind ML, Munnik T, Saidi Y, Goloubinoff P, Harwood JL, Vigh L (2012) Heat shock response in photosynthetic organisms: membrane and lipid connections. Prog Lipid Res 51(3):208-220. doi:10.1016/j.plipres.2012.02.002

Horvath I, Glatz A, Varvasovszki V, Torok Z, Pali T, Balogh G, Kovacs E, Nadasdi L, Benko S, Joo F (1998) Membrane physical state controls the signaling mechanism of the heat shock response in Synechocystis PCC 6803: identification of hsp17 as a "fluidity gene". Proc Natl Acad Sci U S A 95(7):3513-3518

Horváth I, Glatz A, Varvasovszki V, Török Z, Pali T, Balogh G, Kovacs E, Nadasdi L, Benko S, Joo F, Vígh L (1998) Membrane physical state controls the signaling mechanism of the heat shock response in Synechocystis PCC 6803: identification of hsp17 as a "fluidity gene". Proc Natl Acad Sci U S A 95(7):3513-3518

Kumar SV, Wigge PA (2010) H2A.Z-containing nucleosomes mediate the thermosensory response in Arabidopsis. Cell 140(1):136-147. doi:10.1016/j.cell.2009.11.006

Larkindale J, Vierling E (2008) Core genome responses involved in acclimation to high temperature. Plant Physiol 146(2):748-761. doi:10.1104/pp.107.112060

Li M, Doll J, Weckermann K, Oecking C, Berendzen KW, Schoffl $\mathrm{F}$ (2010) Detection of in vivo interactions between Arabidopsis class A-HSFs, using a novel BiFC fragment, and identification of novel class B-HSF interacting proteins. European Journal of Cell Biology 89(2-3):126-132. doi:10.1016/ j.ejcb.2009.10.012

Liu HT, Gao F, Cui SJ, Han JL, Sun DY, Zhou RG (2006) Primary evidence for involvement of IP3 in heat-shock signal transduction in Arabidopsis. Cell Research 16(4):394-400. doi:10.1038/ sj.cr.7310051

Liu HT, Gao F, Li GL, Han JL, Liu DL, Sun DY, Zhou RG (2008) The calmodulin-binding protein kinase 3 is part of heat-shock signal transduction in Arabidopsis thaliana. Plant Journal 55(5):760 773. doi:10.1111/j.1365-313X.2008.03544.x
Mishkind M, Vermeer JEM, Darwish E, Munnik T (2009) Heat stress activates phospholipase D and triggers PIP2 accumulation at the plasma membrane and nucleus. Plant Journal 60(1):10-21. doi:10.1111/j.1365-313X.2009.03933.x

Mittler R, Blumwald E (2010) Genetic engineering for modern agriculture: challenges and perspectives. Annual Review of Plant Biology 61(1):443-462. doi:10.1146/annurev-arplant-042809112116

Mittler R, Finka A, Goloubinoff P (2012) How do plants feel the heat? Trends Biochem Sci 37(3):118-125

Peel MC, Finlayson BL, McMahon TA (2007) Updated world map of the Koppen-Geiger climate classification. Hydrol Earth Syst Sc 11(5):1633-1644

Petesch SJ, Lis JT (2008) Rapid, transcription-independent loss of nucleosomes over a large chromatin domain at Hsp70 loci. Cell 134(1):74-84. doi:10.1016/j.cell.2008.05.029

Petesch SJ, Lis JT (2012) Activator-induced spread of poly(ADP-ribose) polymerase promotes nucleosome loss at Hsp70. Molecular Cell 45(1):64-74. doi:10.1016/ j.molcel.2011.11.015

Plieth C (2006) Aequorin as a reporter gene. Methods in molecular biology 323: 307-328. In: Salinas J, Sanchez-Serrano JJ (eds) Arabidopsis protocols. 2nd edn. Humana, Totowa

Qin D, Wu H, Peng H, Yao Y, Ni Z, Li Z, Zhou C, Sun Q (2008) Heat stress-responsive transcriptome analysis in heat susceptible and tolerant wheat (Triticum aestivum L.) by using wheat genome array. BMC Genomics 9(1):432

Saidi Y, Domini M, Choy F, Zryd JP, Schwitzguebel JP, Goloubinoff P (2007) Activation of the heat shock response in plants by chlorophenols: transgenic Physcomitrella patens as a sensitive biosensor for organic pollutants. Plant Cell Environ 30(6):753763. doi:10.1111/j.1365-3040.2007.01664.x

Saidi Y, Finka A, Chakhporanian M, Zryd JP, Schaefer DG, Goloubinoff P (2005) Controlled expression of recombinant proteins in Physcomitrella patens by a conditional heat-shock promoter: a tool for plant research and biotechnology. Plant Mol Biol 59(5):697-711. doi:10.1007/s11103-005-0889-z

Saidi Y, Finka A, Goloubinoff P (2011) Heat perception and signalling in plants: a tortuous path to thermotolerance. New Phytol 190(3):556-565. doi:10.1111/j.1469-8137.2010.03571.x

Saidi Y, Finka A, Muriset M, Bromberg Z, Weiss YG, Maathuis FJM, Goloubinoff P (2009) The heat shock response in moss plants is regulated by specific calcium-permeable channels in the plasma membrane. Plant Cell 21(9):2829-2843. doi:10.1105/ tpc. 108.065318

Saidi Y, Peter M, Finka A, Cicekli C, Vigh L, Goloubinoff P (2010) Membrane lipid composition affects plant heat sensing and modulates $\mathrm{Ca}^{2+}$-dependent heat shock response. Plant Signal Behav 5(12):1530-1533

Schaefer DG, Zryd JP (1997) Efficient gene targeting in the moss Physcomitrella patens. Plant Journal 11(6):1195-1206

Scharf KD, Berberich T, Ebersberger I, Nover L (2012) The plant heat stress transcription factor (Hsf) family: structure, function and evolution. Bba-Gene Regul Mech 1819(2):104-119. doi:10.1016/j.bbagrm.2011.10.002

Sharma SK, De Los RP, Christen P, Lustig A, Goloubinoff P (2010) The kinetic parameters and energy cost of the Hsp70 chaperone as a polypeptide unfoldase. Nat Chem Biol 6(12):914-920. doi:10.1038/Nchembio.455

Sharma SK, De Los RP, Goloubinoff P (2011) Probing the different chaperone activities of the bacterial HSP70-HSP40 system using a thermolabile luciferase substrate. Proteins 79(6):1991-1998. doi:10.1002/Prot.23024

Torok Z, Horvath I, Goloubinoff P, Kovacs E, Glatz A, Balogh G, Vigh L (1997) Evidence for a lipochaperonin: association of active protein-folding GroESL oligomers with lipids can stabilize 
membranes under heat shock conditions. Proc Natl Acad Sci U S A 94(6):2192-2197

Tunc-Ozdemir M, Tang C, Rahmati Ishka M, Brown E, Groves NR, Myers CT, Rato C, Poulsen LR, McDowell S, Miller G, Mittler R, Harper JF (2012) A cyclic nucleotide-gated channel (CNGC16) in pollen is critical for stress tolerance in pollen reproductive development. Plant Physiol. doi:10.1104/ pp. 112.206888

Veinger L, Diamant S, Buchner J, Goloubinoff P (1998) The small heat-shock protein IbpB from Escherichia coli stabilizes stress- denatured proteins for subsequent refolding by a multichaperone network. J Biol Chem 273(18):11032-11037

Voellmy R, Boellmann F (2007) Chaperone regulation of the heat shock protein response. Adv Exp Med Biol 594:89-99

Wheeler GL, Brownlee C (2008) Ca2+ signalling in plants and green algae-changing channels. Trends Plant Sci 13(9):506-514. doi:10.1016/j.tplants.2008.06.004

Zelman AK, Dawe A, Berkowitz GA, Gehring C (2012) Evolutionary and structural perspectives of plant cyclic nucleotide gated cation channels. Frontiers in Plant Science. doi: 10.3389/fpls.2012.00095 